\title{
Can a Digital Therapy Using Sound and Light Reset the Balance of Alzheimer's Disease?
}

\author{
Julia N. Wond, Carson Will* \\ Group of Neuropharmacology and Neurophysiology, Division of Neuroscience, The BASE, Chapel Hill, NC 27510, USA \\ *: All correspondence should be sent to: Dr. Carson Will. \\ Author's Contact: Julia N. Wond, PhD, MPH, E-mail: julia.wond@basehq.org; Carson Will, PhD, E-mail: carson.will@basehq.org \\ DOI: https://doi.org/10.15354/si.22.pe005 \\ The authors declare no competing interest.
}

\begin{abstract}
Alzheimer's disease (AD) is a degenerative cognition-declining disease with no clear understanding of the underlying mechanisms. Currently, no effective therapeutics are available for AD. Amyloid- $\beta$ (A- $\beta$ ) plaques and tau tangles were considered as the contributing factors to the development of $A D$. In contrast, controversial exists due to efforts focusing on A- $\beta$ as a pharmacological therapeutic target was failed. Emerging evidence appeared for the external stimuli applied through vision (LED) and hearing $(\sim 40 \mathrm{~Hz})$ to certain intensity to dementia subjects with promising results such as reducing $A-\beta$ and tau tangles in the brain tissue, increasing the brain volume reducing the decline of daily activities and mental status. This optogenetic and sound-derived digital therapeutic maneuver provides a striking way for conquering the development of AD.
\end{abstract}

Keywords: Alzheimer's Disease; Vision; Hearing; Optogenetics; Neuronal Activities; Amyloid- $\beta$; Tau Tangles

Science Insights, 2022 January 31; Vol. 40, No. 2, pp.427-430.

() 2022 Insights Publisher. All rights reserved.

Creative Commons Non Commercial CC BY-NC: This article is distributed under the terms of the Creative Commons Attribution-NonCommercial 4.0 License which permits non-commercial use, reproduction and distribution of the work without further permission provided the original work is attributed by the Insights Publisher.

A LZHEIMER'S disease (AD), a global public health priority recognized by World Health Organization, is the most common cause of dementia $(50 \%-75 \%)$ affecting daily activities through intervening cognition. The number of people suffering from AD is extremely large. It is predicted that by 2050 , the world population with $\mathrm{AD}$ would be tripled, and the annual cost of dementia in the USA alone may exceed $\$ 600$ billion USD (1). AD is roughly doubling in prevalence every 5 years after age $65(1,2)$.

Accordingly, between 1998 and 2017, 146 new AD drugs have failed in clinical trials worldwide, the clinical success rate is only $2.7 \%$ (3). At present, there are only 5 kinds of AD treatment drugs approved by the FDA (including a compound preparation), all of which can only improve the symptoms of $\mathrm{AD}$, and cannot really delay the disease process (4). The repeated failures of new drugs and the successive failures of top companies with first-class R\&D capabilities have even caused some scholars to doubt whether our cognitive basis for $\mathrm{AD}$ is wrong.

At the 15th International Conference on Alzheimer's and Parkinson's Disease (AD/PDTM2021) in 2021 (5), Cognito Therapeutics presented data from a Phase II clinical study of digital therapy gamma frequency neuromodulation. The therapy was developed from prior studies that found $40 \mathrm{~Hz}$ sound/stimulation light can reduce $\beta$-amyloid in the brain and improve cognition (6-8). This therapy is carried out through a device called GammaSense, which is completely non-invasive and has good safety and tolerability. From the data, 1-hour daily, 6-month treatment can significantly delay disease progression in patients with mild to moderate $\mathrm{AD}$, slowing the decline in scores of Alzheimer's Disease Cooperative Study - Activities of Daily 


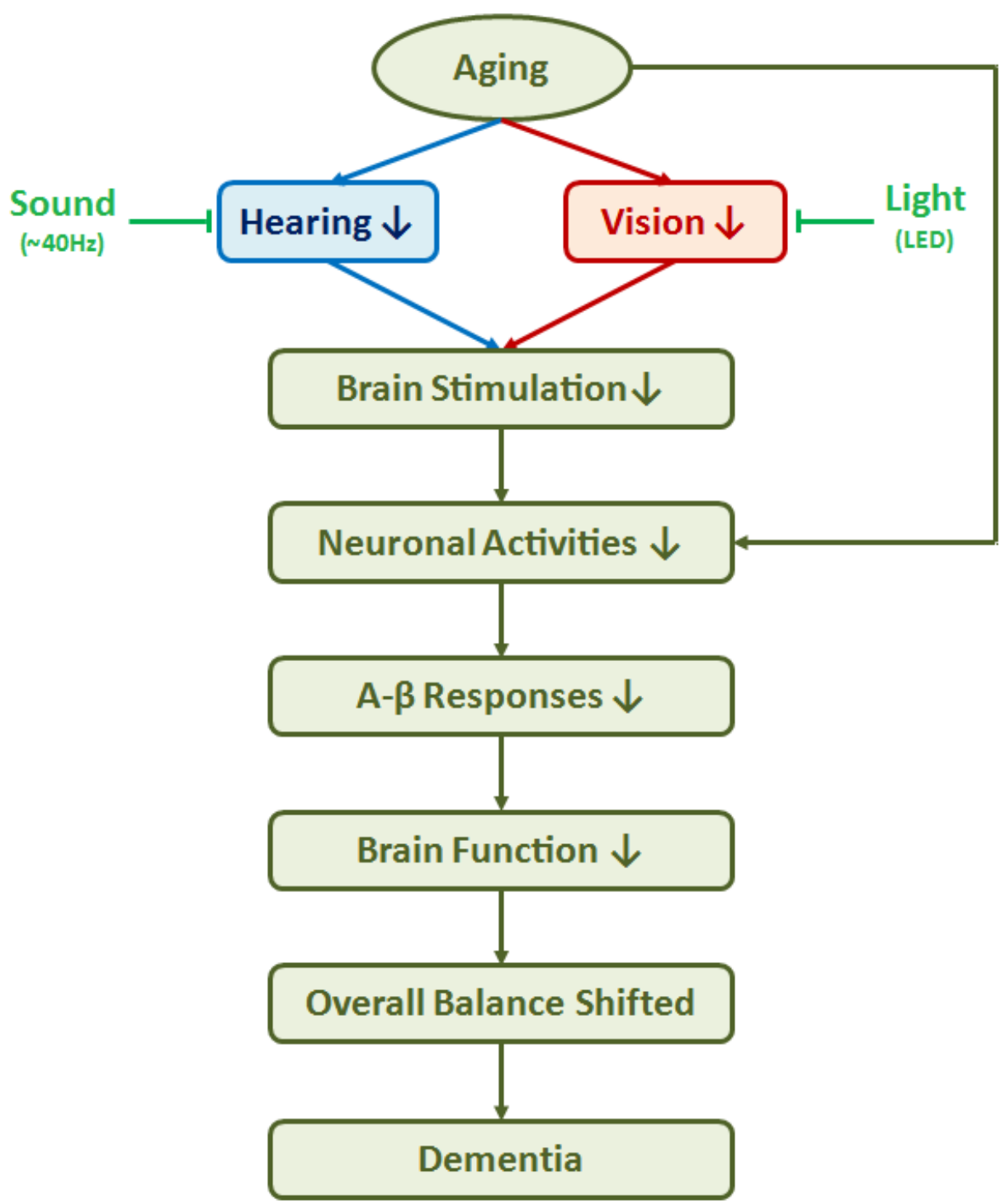

Figure 1. Aging-related Changes in Neuronal Activities and Cognition Decline.

Living (ADCS-ADL) by $84 \%$, and slowed the Mini-Mental State Examination (MMSE) scores by $83 \%$, and brain shrinkage was significantly reduced by $61 \%$ (9).

In the face of $\mathrm{AD}$ with complex mechanisms and many potential targets, the solution proposed in this paper turned out to be LED lights (6)? In the study, Iaccarino et al. noticed a phe-nomenon that in the brains of patients with diseases such as brain injury, schizophrenia, and $\mathrm{AD}$, there is often confusion in the gamma brain waves with frequencies of $30-90 \mathrm{~Hz}$ (6). Brain waves can be said to be the visualization of neuronal connections in the brain, and the disorder of gamma waves is likely to mean the disorder of neuron functions. This cannot help making the researchers guess, if the gamma wave can be restored by certain means, can the normal function of the neurons be restored? Initial attempts were achieved through optogenetics, which is the modulation of neuronal activity through implanted optical fibers and photoreceptors on nerve cells (10). The ex- perimental results are very surprising. Using a frequency of $40 \mathrm{~Hz}$, only one hour of treatment can reduce amyloid- $\beta$ (A- $\beta$ ) in the brain of $\mathrm{AD}$ mice by $40 \%-50 \%$. The researchers asked what about using an external light source? Through both eyes, these lights can also reach deep into the nerves. Sure enough, using LED lights with a light source frequency of $40 \mathrm{~Hz}$ to illuminate the mice, the frequency of gamma waves in the visual cortex of the mouse brain really keeps up with the rhythm, and the A- $\beta$ was reduced with the reduction of the concentration of tau protein.

This study is just the beginning of a series of studies. More than two years later, they published a paper again (6), pointing out that in addition to light stimulation, $40 \mathrm{~Hz}$ sound stimulation can also reduce A- $\beta$ in the mouse brain, and the stimulation range is wider. Light can only affect the visual cortex, while sound can touch the auditory cortex and CA1 area in the hippocampus $(11,12)$. Combined with sound and light, the synergetic 
effect of " $1+1>2$ " can be achieved, which further expands the scope of the affected brain area. After one hour a day and one week of treatment, the total plaque volume in the prefrontal cortex of the mice was reduced by $37 \%$.

Another study presented a detailed explanation (13). It turns out that the regulation of gamma waves mainly induces scavengers in the brain, i.e., the morphological changes and gene expression changes of microglia, reduces the inflammatory response of microglia, and also protects neuronal synaptic function.

According to the trial design published on clinicaltrials.gov (14), the OVERTURE trial is a phase I/II randomized controlled, single-blind, multicenter study. They expect to recruit $60 \mathrm{pa}-$ tients aged 55 years and older with mild to moderate dementia (MMSE score 14-26), subjects were randomly assigned 2:1 to treatment and control groups for one hour per day for six months and the control group used a sham device. The trial will use MMSE and ADCS-ADL to assess cognitive and memory function, and use structural magnetic resonance imaging (MRI) to assess changes in patients' brain volume. Published clinical trial data showed that 76 mild-to-moderate $\mathrm{AD}$ patients over the age of 50 were actually recruited. During the 6-month treatment period, gamma frequency neuromodulation therapy was safe and well-tolerated; compared with the control group, the ADCS-ADL score decreased by $84 \%$ and the MMSE score decreased by $83 \%$ in the treatment group, which was associated with AD Brain shrinkage and brain volume loss decreased by $61 \%$. Given the dramatic improvement in brain atrophy, it is believed that gamma-frequency neuromodulation therapy has the potential to actually change the course of the disease. If verified in a larger-scale study, it will undoubtedly bring a huge medical breakthrough to the treatment of AD. Of course, this will also be the first digital therapy to truly delay the occurrence of $\mathrm{AD}$.

Light and sound are key stimuli for the initiation of human cognitive development. At any age, light and sound are important means of information acquisition, neuronal activation, and emotional function (15). However, in late adulthood, with the increase of age, the organs of the human body begin to age, in which the decline in vision and hearing gradually reduces the amount of information transmitted to the brain. This will lead to a decrease in the external stimulation of the brain (16). At this time, along with the aging of the brain itself, the sensitivity to information stimulation decreases. The result of the combination of the two is a sharp decline in the function and activity of brain neurons (17). This will be accompanied by the production of a protective response in the brain, which is manifested by increased A- $\beta$ synthesis and tau tangles $(18,19)$. The increase in the amount of both $A-\beta$ and tau tangles makes the functional balance of brain neurons shift after a period of accumulation, and its external manifestation is the occurrence of various dementia-related neurological symptoms (20). Therefore, using external sound waves of a certain frequency and light waves of certain intensity to stimulate the brain at the above stage, according to the available data, has certain feasibility. By combining these two ways to form a digitally controlled stimulator such as a virtual reality headset and applying it to a suitable group of people, it has practical operability (Figure 1)..

\section{References}

1. Lane CA, Hardy J, Schott JM. Alzheimer's disease. Eur J Neurol 2018; 25(1):59-70. DOI: https://doi.org/10.1111/ene.13439

2. Scheltens $P$, De Strooper B, Kivipelto M, Holstege $H$, Chételat G, Teunissen CE, Cummings J, van der Flier WM. Alzheimer's disease. Lancet 2021; 397(10284):1577-1590. DOI: https://doi.org/10.1016/S0140-6736(20)32205-4

3. Lao K, Ji N, Zhang X, Qiao W, Tang Z, Gou X. Drug development for Alzheimer's disease: review. J Drug Target 2019; 27(2):164-173. DOI: https://doi.org/10.1080/1061186X.2018.1474361

4. Cummings J, Lee G, Zhong K, Fonseca J, Taghva K. Alzheimer's disease drug development pipeline: 2021. Alzheimers Dement (NY) 2021; 7(1):e12179. DOI: https://doi.org/10.1002/trc2.12179

5. The 15th International Conference on Alzheimer's and Parkinson's Disease. AD/PDTM 2021. March 09-14, 2021. Last access: January 28, 2022. Available at: https://adpd2021.kenes.com/

6. Martorell AJ, Paulson AL, Suk HJ, Abdurrob F, Drummond GT, Guan W, Young JZ, Kim DN, Kritskiy

O, Barker SJ, Mangena V, Prince SM, Brown EN, Chung K, Boyden ES, Singer AC, Tsai LH. Multi-sensory gamma stimulation ameliorates Alzheimer's-associated pathology and improves cognition. Cell 2019; 177(2):256-271.e22. DOI: https://doi.org/10.1016/i.cell.2019.02.014

7. Adaikkan C, Middleton SJ, Marco A, Pao PC, Mathys H, Kim DN, Gao F, Young JZ, Suk HJ, Boyden ES, McHugh TJ, Tsai LH. Gamma entrainment binds higher-order brain regions and offers neuroprotection. Neuron 2019; 102(5):929-943.e8. DOI: https://doi.org/10.1016/j.neuron.2019.04.011

8. laccarino HF, Singer AC, Martorell AJ, Rudenko A, Gao F, Gillingham TZ, Mathys H, Seo J, Kritskiy O, Abdurrob F, Adaikkan C, Canter RG, Rueda R, Brown EN, Boyden ES, Tsai LH. Gamma frequency entrainment attenuates amyloid load and modifies microglia. Nature 2016; 540(7632):230-235. DOI: https://doi.org/10.1038/nature20587. Erratum in: Nature 2018; 562(7725):E1.

9. Cognito Therapeutics announces positive phase 2 results as first digital therapeutic to improve memory, cognition, functional abilities and reduce brain atro- 
phy in Alzheimer's disease. Businesswire. Last access: January 28, 2022. Available at:

https://www.businesswire.com/news/home/20210309 005355/en

10. Wang F. Optogenetics: The key to deciphering and curing neurological diseases. Sci Insig 2020; 35(4):224-235. DOI: https://doi.org/10.15354/si.20.re081

11. Smith $\mathrm{PH}$, Manning KA, Uhlrich DJ. Evaluation of inputs to rat primary auditory cortex from the suprageniculate nucleus and extrastriate visual cortex. J Comp Neurol 2010; 518(18):3679-3700. DOI: https://doi.org/10.1002/cne.22411

12. Deneux T, Harrell ER, Kempf A, Ceballo S, Filipchuk A, Bathellier B. Context-dependent signaling of coincident auditory and visual events in primary visual cortex. Elife 2019; 8:e44006. DOI: https://doi.org/10.7554/eLife.44006

13. Adaikkan C, Middleton SJ, Marco A, Pao PC, Mathys H, Kim DN, Gao F, Young JZ, Suk HJ, Boyden ES, McHugh TJ, Tsai LH. Gamma entrainment binds higher-order brain regions and offers neuroprotection. Neuron 2019; 102(5):929-943.e8. DOI:

https://doi.org/10.1016/j.neuron.2019.04.011

14. Cognito Therapeutics, Inc. Multi-center study of sensory stimulation to improve brain function (Overture). ClinicalTrials.gov Identifier: NCT03556280. Last access: January 28, 2022. Available at: https://clinicaltrials.gov/ct2/show/NCT03556280
15. Hori S, Mori K, Mashimo T, Seiyama A. Effects of light and sound on the prefrontal cortex activation and emotional function: A functional near-infrared spec troscopy Study. Front Neurosci 2017; 11:321. DOI: https://doi.org/10.3389/fnins.2017.00321

16. Dodig S, Čepelak I, Pavić I. Hallmarks of senescence and aging. Biochem Med (Zagreb) 2019; 29(3):030501. doi: https://doi.org/10.11613/BM.2019.030501

17. Fazakerley JK. Neurovirology and developmental neurobiology. Adv Virus Res 2001; 56:73-124. DOI: https://doi.org/10.1016/s0065-3527(01)56005-4

18. Weaver DF. Amyloid beta is an early responder cytokine and immunopeptide of the innate immune system. Alzheimers Dement (NY) 2020; 6(1):e12100. DOI: https://doi.org/10.1002/trc2.12100

19. Kuchibhotla KV, Wegmann S, Kopeikina KJ, Hawkes J, Rudinskiy N, Andermann ML, Spires-Jones TL, Bacskai BJ, Hyman BT. Neurofibrillary tangle-bearing neurons are functionally integrated in cortical circuits in vivo. Proc Natl Acad Sci USA 2014; 111(1):510-514 DOI: https://doi.org/10.1073/pnas.1318807111

20. Rajmohan R, Reddy PH. Amyloid-beta and phosphorylated tau accumulations cause abnormalities at synapses of Alzheimer's disease neurons. J Alzheimers Dis 2017; 57(4):975-999. DOI: https://doi.org/10.3233/JAD-160612 